\title{
Воспрепятствование осуществлению правосудия и производству предварительного расследования: вопросы теории и практики
}

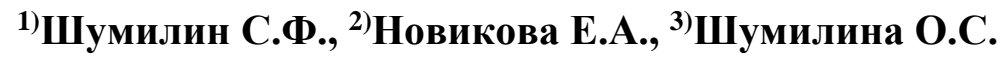 \\ ${ }^{1,2)}$ Белгородский юридический институт МВД России имени И.Д. Путилина, \\ Россия, 308024, г. Белгород, ул. Горького, 71 \\ 3) Белгородский государственный национальный исследовательский университет, \\ Россия, 308015, г. Белгород, ул. Победы, 85 \\ E-mail: belui@mvd.ru; stepanyuk@bsu.edu.ru
}

\begin{abstract}
Аннотация. Решение задач по осуществлению судом правосудия и формированию необходимой для этого фактической основы органами предварительного расследования обеспечивается уголовно-правовыми средствами: привлечением к уголовной ответственности за воспрепятствование осуществлению правосудия и производству предварительного расследования. Вследсвие неопределенности истолкования ряда терминов («правосудие», «отправление правосудия» и «иные лица, участвующие в отправлении правосудия») в уголовно-правовых нормах, устанавливающих указанную ответственность, следователи и судьи нередко допускают ошибки. Указанные термины являются предметом изучения в правовой литературе, однако вне поля зрения исследователей остается следственно-судебная практика их применения. Авторами рассмотрены причины сложившегося положения на основе анализа опубликованной следственной и судебной практики и сформулированы предложения по совершенствованию уголовного законодательства и практики его применения.
\end{abstract}

Ключевые слова: уголовно-правовой конфликт, отправление правосудия, участвующие в отправлении правосудия, воспрепятствование, квалификация.

Для цитирования: Шумилин С.Ф., Новикова Е.А., Шумилина О.С. 2020. Воспрепятствование осуществлению правосудия и производству предварительного расследования: вопросы теории и практики. NOMOTHETIKA: Философия. Социология. Право. 45 (4): 792-800. DOI 10.18413/2712746X-2020-45-4-792-800

\section{Obstruction of Justice and Preliminary Investigation: Theory and Practice}

\author{
${ }^{1)}$ Sergey F. Shumilin, ${ }^{2)}$ Ekaterina A. Novikova, ${ }^{3)}$ Oksana S. Shumilina \\ ${ }^{1), 2)}$ Putilin Belgorod Law Institute of the Ministry of the Interior of Russia, \\ 71 Gorky St, Belgorod, 308024, Russia \\ ${ }^{3)}$ Belgorod National Research University, \\ 85 Pobeda St, Belgorod, 308015, Russia \\ E-mail: belui@mvd.ru; stepanyuk@bsu.edu.ru
}

\begin{abstract}
The solution of tasks on the administration of justice by the court and the formation of the necessary factual basis by the preliminary investigation bodies is ensured by criminal law means: criminal prosecution for obstruction of the administration of justice and the production of a preliminary investigation. Due to the ambiguity in the interpretation of a number of terms ("justice", "administration of justice" and "other persons involved in the administration of justice") in the criminal law provisions
\end{abstract}


establishing this responsibility, investigators and judges often make mistakes. These terms are the subject of study in the legal literature, however, the investigative and judicial practice of their application remains outside the field of view of researchers. The authors considered the reasons for the current situation on the basis of an analysis of the published investigative and judicial practice and formulated proposals for improving the criminal legislation and the practice of its application.

Keywords: law enforcement, criminal conflict, administration of justice, persons involved in the administration of justice, obstruction, qualification.

For citation: Shumilin S.F., Novikova E.A., Shumilina O.S. 2020. Obstruction of Justice and Preliminary Investigation: Theory and Practice. NOMOTHETIKA: Philosophy. Sociology. Law series. 45 (4): $792-$ 800 (in Russian). DOI 10.18413/2712-746X-2020-45-4-792-800

\section{Введение}

Российское государство, выполняя одну из обязательных внутренних функций функцию охраны правопорядка - устанавливает запрет на совершение деяний, которые могут посягать (и посягают) на существующий в государстве правопорядок. При этом запрет за совершение наиболее опасных деяний, именуемых в законодательстве преступлениями, установлен в нормах Особенной части Уголовного кодекса Российской Федерации (далее - УК РФ). Такие нормы, несомненно, оказывают предупредительное воздействие на правосознание граждан, а также иных лиц, находящихся на территории России, однако не в состоянии полностью исключить совершение преступлений. Данное обстоятельство является причиной создания системы государственных органов, на которые возлагается выполнение функции разрешения уголовно-правовых конфликтов, возникающих в каждом случае обнаружения признаков совершения преступления. По законодательству России в эту систему входят органы предварительного расследования, прокуроры и суды общей юрисдикции (далее - органы уголовной юстиции).

Для выполнения функции разрешения уголовно-правовых конфликтов, органы уголовной юстиции уполномочены в пределах установленной Уголовно-процессуальным кодексом Российской Федерации (далее - УПК РФ) компетенции на производство предварительного расследования и судебное разбирательство по уголовным делам.

Как свидетельствует история становления и развития российского уголовного процесса, заинтересованные в исходе уголовного дела лица в целях принятия органами уголовной юстиции незаконных, но выгодных этим лицам решений по уголовным делам нередко препятствуют производству предварительного расследования и судебного разбирательства. В связи с этим российский законодатель установил уголовную ответственность за совершение деяний, которые способны создавать препятствия осуществлению правосудия и производству предварительного расследования. При этом нормы УК РФ, устанавливающие такую ответственность, сконструированы с использованием терминов, которые допускают различное их истолкование. Главным образом это относится к таким терминам, как «правосудие», «отправление правосудия» и «иные лица, участвующие в отправлении правосудия».

Изучение опубликованной следственно-судебной практики применения уголовноправовых норм, конструктивными элементами которых являются перечисленные термины, приводит к выводу о том, что их неопределенность нередко является причиной неправильной квалификации преступлений, предусмотренных ст.ст. 294-297 УК РФ, в постановлениях о привлечении в качестве обвиняемых, обвинительных актах и приговорах судов. Разумеется, указанные термины являются предметом исследования в правовой литературе. Однако при этом вне поля зрения авторов нередко остается следственно-судебная практика применения исследуемых терминов, что не способствует устранению их неопределенности. 
В настоящей статье с учетом опубликованной следственной и судебной практики предпринята попытка устранить отдельные пробелы в исследовании терминологии норм УК РФ, в которых установлена уголовная ответственность за действия, направленные на воспрепятствование осуществлению правосудия и производству предварительного расследования.

\section{Понятия «правосудие» и «осуществление правосудия» в теории и уголовно-процессуальном законодательстве}

Современная правовая теория оперирует двумя понятиями правосудия: в широком и узком смысле слова. В настоящее время трудно установить, когда именно сформировались различия в определении данного понятия. Во всяком случае, комментируя статьи главы 7 («О противодействии правосудию») Уголовного уложения 1903 года, Н.С. Таганцев писал о том, что понятие правосудия следует рассматривать в широком общежитейском или в тесном, строго техническом процессуальном либо в юридическом смысле этого слова.

Правосудие в широком смысле он отождествлял со справедливостью, а осуществление правосудия понимал как общегражданскую и общеслужебную обязанность. Правосудие в процессуальном смысле Н.С. Таганцев рассматривал как «особую отрасль государственной деятельности, осуществляемую через специально на то уполномоченные судебные органы, т.е. деятельность лиц, не только облечённых функциями судебного свойства, но и принадлежащих именно к числу судебных органов государства; таким образом, сфера правосудия ограничивается исключительно лишь деятельность судей (и содействующих им органов власти), выражающейся при том в участии их в обставленном известными формами и обрядами уголовном или гражданском процессе». Понятие правосудия в юридическом смысле, по мнению Таганцева, «означает законосообразную деятельность каждого такого органа власти, который уполномочен законом произнести подлежащее понудительному исполнению решение по вопросу об уголовной и дисциплинарной ответственности или по спору о правах участвующих в деле сторон, а равно и органов власти, содействующих им в этой их деятельности [Таганцев, 1904, с. 1071-1073].

В теории уголовного права и процесса советского периода приведенный выше подход к определению понятий «правосудие» и «осуществление правосудия» не нашел широкого распространения. На наш взгляд, это объясняется тем, что в п. «б» ст. 4 Закона РСФСР от 27.10.1960 «О судоустройстве РСФСР» и в п. 2 ст. 4 Закон РСФСР от 08.07.1981 «О судоустройстве РСФСР» (ред. от 07.05.2009) было закреплено положение, согласно которому правосудие в РСФСР осуществляется путем «рассмотрения в судебных заседаниях уголовных дел и применения установленных законом мер наказания к лицам, виновным в совершении преступления, либо оправдания невиновных».

Приведенные положения действовали до издания Федерального конституционного закона от 07.02.2011 № 1-ФКЗ «О судах общей юрисдикции в Российской Федерации», однако еще во время их действия в теории уголовного права сформировалась тенденция к расширительному толкованию понятий правосудия и осуществления правосудия. Так, например, А.В. Бриллиантов и Н.Р. Косевич, полемизируя с авторами, по мнению которых в главе 31 УК РФ законодатель поставил под охрану только деятельность органов, разрешающих дело по существу, утверждают, что «под осуществлением правосудия как объекта уголовно-правовой охраны следует понимать специфический вид государственной деятельности, осуществляемой только судом при рассмотрении конституционных, уголовных, гражданских, административных дел с точным соблюдением особого порядка рассмотрения и разрешения дел - судопроизводством и только определенными законом способами, а именно путем рассмотрения и разрешения в судебных заседаниях в установленном процессуальным законом порядке, а также деятельность органов дознания, предва- 
рительного следствия и деятельность по исполнению судебных решений, осуществляемую судебными приставами, уголовно-исполнительной системы и т.д.» (выделено нами. - Aвт.) [Бриллиантов, Косевич, 2008, с. 35-36].

С приведенным определением правосудия, если его экстраполировать на уголовное судопроизводство, нельзя согласиться, поскольку авторы смешивают осуществление правосудия и объекты уголовно-правовой охраны: деятельность суда по осуществлению правосудия, деятельность органов предварительного расследования по формированию фактической основы для осуществления правосудия и деятельность по исполнению акта правосудия.

С предложенным авторами определением нельзя согласится и по другой причине: оно противоречит понятию осуществления правосудия в уголовном судопроизводстве, которое вытекает из содержания ст. 8.1 УПК РФ. По смыслу части второй данной статьи формой осуществления правосудия в уголовном процессе является только рассмотрение и разрешение уголовных дел.

По этой же причине вызывает возражение утверждение о том, что рассмотрение судьей жалоб в порядке, установленном ст. 125 УПК РФ, является формой осуществления правосудия [Евстигнеева, 2019] и что деятельность лиц, участвующих в проверке сообщения о преступлении, представляет собой содействие суду в осуществлении функции правосудия [Юшина, 2015].

Как уже было отмечено выше, согласно ч. 2 ст. 8.1 УПК РФ осуществление судами правосудия возможно только по находящимся в их производстве уголовным делам. Между тем в соответствии с ч. 3 ст. 29 УПК РФ судья рассматривает в порядке, установленном ст. 125 УПК РФ, жалобы по уголовным делам, находящимся в производстве органов предварительного расследования. Таким образом, противоправные деяния, совершенные во время рассмотрения судьями жалоб, по правилам, установленным ст. 125 УПК РФ, могут рассматриваться как воспрепятствование производству предварительного расследования, но не осуществлению правосудия.

Суждение Ю.В. Юшиной о том, что деятельность лиц, участвующих в проверке сообщений о преступлениях, целесообразно взять под уголовно-правовую защиту, заслуживает внимания и дальнейшего обсуждения. Как показывает следственная практика, уклонение лиц, от которых может быть получена информация, необходимая для разрешения вопроса о наличии или отсутствии в содеянном признаков преступления, от явки и дачи объяснения или представления образцов для сравнительного исследования представляет собой серьезное препятствие для проведения проверок сообщений о преступлениях и своевременного разрешения сообщений. Причиной такого поведения может быть воздействие на носителей релевантной информации со стороны лиц, заинтересованных в том, чтобы не были возбуждены уголовные дела. Однако при всей значимости участия тех или иных лиц в следственных и иных процессуальных действиях, производимых в ходе проверки сообщений о преступлениях, нет оснований для признания их деятельности содействием осуществлению правосудия. На данном этапе уголовного судопроизводства даже нет еще уголовного дела, наличие которого является обязательным условием для осуществления правосудия.

На наш взгляд, следует согласиться с Е.В. Рябцевой, по мнению которой правосудие можно определить «как государственную деятельность суда по рассмотрению уголовного дела по существу, принятию решения о признании лица виновным или невиновным, назначению виновному справедливого наказания в установленной законом процессуальной форме и принятию мер по возмещению вреда, связанного с уголовным преследованием» [Рябцева, 2010, с. 12]. Аналогичную позицию при определении понятия правосудия занимают и другие авторы [Прокудина, 2010; Банников, 2017; Бимбинов и др, 2018].

Вместе с тем приведенное определение правосудия не в полной мере включает в себя содержание правосудия. В теории уголовного права и процесса, в следственной и судебной практике нередко возникает вопрос о том, является ли правосудием рассмотрение 
уголовных дел судом апелляционной инстанции. Основанием для этого служит привлечение к уголовной ответственности по ч. 1 ст. 294 УК РФ за уничтожение (повреждение) осужденными (полностью или частично) материалов дела, подлежащих направлению в суд апелляционной инстанции, либо материалов, представленных в суд для рассмотрения тех или иных вопросов, возникающих на стадии исполнения приговора.

Суды общей юрисдикции признают содеянное вмешательством в осуществление правосудия и квалифицируют по ч. 1 ст. 294 УК РФ (см., например, приговор Можгинского городского суда Удмуртской Республики № 1-192/2019 1-4/2020 от 10.01.2020 по делу № 1-192-2019) ${ }^{1}$.

На наш взгляд, такое решение вопроса, хотя и не соответствует понятию осуществления правосудия, вытекающему из содержания ч. 2 ст. 8.1 УПК РФ, однако является правильным. К такому выводу приводят следующие рассуждения. Суд апелляционной инстанции проверяет законность и обоснованность приговора, который является актом правосудия, а значит, его действия по рассмотрению уголовного дела, в свою очередь, являются осуществлением правосудия. Это находит свое подтверждение и в том, что по результатам рассмотрения уголовного дела суд апелляционной инстанции может постановить новый приговор. Отсюда следует вывод о том, что деяния, препятствующие направлению уголовных дел в суд апелляционной инстанции, фактически препятствуют осуществлению дальнейшего правосудия по уголовным делам.

«Правосудие, - как справедливо отмечает Председатель Верховного Суда РФ В.М. Лебедев, - осуществляется посредством рассмотрения в судебных заседаниях гражданских, уголовных и иных дел в установленной законом процессуальной форме. Причем это не только разбирательство дел судом первой инстанции, но и пересмотр вынесенных им решений вышестоящими судами - то есть, апелляционной, кассационной и надзорной инстанциями, а также производство в суде по вновь открывшимся обстоятельствам» [Анишина В.И. и др., 2011, с. 446].

Осуществлением правосудия является также рассмотрение судьями вопросов, возникающих в связи с исполнением приговоров (ст. 397 УПК РФ). Это объясняется тем, что таким образом вносятся изменения в порядок исполнения акта правосудия.

\section{Уголовно-процессуальные последствия неопределенности понятия «осуществление правосудия»}

Неопределенность понятия «осуществление правосудия» в уголовном судопроизводстве порождает ряд вопросов проблемного характера. Одним из них является вопрос о содержании термина «иные лица, участвующие в отправлении правосудия», который законодатель включил в диспозиции ст. 295, ч. 1 ст. 296, ч. 1 ст. 297 и ч. 1 ст. 298.1 УК РФ. В теории уголовного права и процесса почти общепризнано, что «иными лицами, участвующими в отправлении правосудия» являются только арбитражные заседатели [Лобанова, 2005. с. 91; Бриллиантов, Косевич, 2008, с. 55]. При этом Л.В. Лобанова предлагает заменить в соответствующих статьях УК РФ термин «иные лица, участвующие в отправлении правосудия» на термин «арбитражные заседатели». Высказанное мнение заслуживает поддержки по следующей причине.

В следственной практике достаточно широкое распространение получила квалификация угрозы убийством, причинением вреда здоровью, уничтожением или повреждением имущества в отношении прокурора по ч. 1 ст. 296 УК РФ, оскорбления прокурора по ч. 2 ст. 297 УК РФ как преступлений, совершенных в отношении «иного лица, участвующего в отправлении правосудия». Суды, как правило, изменяют квалификацию, соответственно,

1 Судебные и нормативные акты Российской Федерации. [Электронный ресурс]. https://sudact.ru/regular/doc/T6h4foVRQeWZ/ -Дата доступа: 15.10.2020 
на ч. 2 ст. 296 и ч. 1 ст. 297 УК РФ, которые предусматривают уголовную ответственность за совершение указанных действий в отношении прокурора не как «иного лица, участвующего в отправлении правосудия», а как участника судебного разбирательства.

Так, например, оскорбления, высказанные осужденным Н. после оглашения приговора в отношении прокурора, который поддерживал обвинение в судебном разбирательстве, дознаватель квалифицировал как преступление, совершенное в отношении «иного лица, участвующего в отправлении правосудия» по ч. 2 ст. 297 УК РФ.

Суд первой инстанции, квалифицируя в приговоре деяния Н., отметил, в частности: «прокурор является участником судебного разбирательства, в данном случае по уголовному делу, а не лицом, участвующим в отправлении правосудия, поэтому действия подсудимого следует переквалифицировать с ч. 2 ст. 297 УК РФ по ч. 1 ст. 297 УК РФ» ${ }^{2}$.

Однако и суды первой инстанции тоже допускают ошибки, квалифицируя оскорбления, высказанные в отношении прокуроров. В частности, Пеновский районный суд Тверской области признал Смирнова Ю.Г. виновным в совершении преступления, предусмотренного ч. 2 ст. 297 УК РФ,- оскорбление прокурора как иного участника судебного разбирательства. Исправляя допущенную ошибку, Тверской областной суд в своем постановлении отметил: «Прокурор в отправлении правосудия не участвует, поскольку, будучи участником судебного разбирательства, лишь выполняет свойственные ему процессуальные функции в стадии судебного разбирательства при рассмотрении уголовного дела. Поэтому, в силу закона, он может выступать потерпевшим по преступлению, предусмотренному ч. 1 ст. 297 УК РФ»².

При изучении опубликованной судебной практики авторами был обнаружен случай, когда следователь, формулируя обвинение по факту клеветы в отношении председателя городского суда, рассматривающего уголовное дело в судебном разбирательстве, квалифицировал действия подсудимого С. как «клевету в отношении иного лица, участвующего в отправлении правосудия (выделено нами. - Авт.), в связи с рассмотрением дела в суде». Суд первой инстанции не согласился с такой формулировкой и возвратил уголовное дело прокурору по основанию, предусмотренному п. 1 ч. 1 ст. 237 УПК РФ 3.

В постановлениях о привлечении в качестве обвиняемого, в обвинительных заключениях и обвинительных приговорах зачастую содержатся внутренне противоречивые формулировки. Так, например, в приговоре Неманского городского суда содержится формулировка, согласно которой суд квалифицировал преступные действия Серафимовича А.Н. по ч. 2 ст. 296 УК РФ «как угроза уничтожением имущества в отношении лица, участвующего в отправлении правосудия, совершенная в отношении прокурора (выделено нами. - Авт.) в связи с рассмотрением дел в суде» ${ }^{4}$.

${ }^{1}$ Приговор Чулымского районного суда Новосибирской области от 20 мая 2013 г. // https://sudact.ru/regular/doc/yu8heUR8cWJr/ (Дата доступа: 22.10.2020); приговор Сарапульского городского суда Удмуртской Республики № 1-111/2018 от 29 ноября 2018 г. по делу № 1-111/2018 // https://sudact.ru/regular/doc/vNobjAJ56Clb/ (Дата доступа: 16.10.2020); приговор Ординского районного суда Пермского края № 1-5/2019 1-69-2018 от 7 февраля 2019 г. по делу № 1-5/2019 // https://sudact.ru/regular/doc/DtIH4ZetWags/ (Дата доступа: 23.10.2020)

2 Постановление Тверского областного суда № 44У-99/2017 4У-465/2017 от 24 июля 2017 г. по делу № 44У-99/2017 // https://sudact.ru/regular/doc/HYymLKZ0sGNx/ (Дата доступа: 22.10.2020).

3 Постановление Лермонтовского городского суда Ставропольского края № 1-35/14 135/2014 от 9 июля 2014 г.// https://sudact.ru/regular/doc/FSmczvbvqWxJ/ (Дата доступа: 23.10.2020).

${ }^{4}$ Приговор Неманского городского суда Калининградской области № 1-115/2019 от 7 ноября 2019 г. по делу №1-115/2019 // https://sudact.ru/regular/doc/5dhrrpVi8UdT/ ; Приговор Тома- 


\section{Заключение}

Проведенное исследование затрагивает лишь некоторые вопросы теории и практики применения норм главы 31 УК РФ, и поэтому не является окончательным. Вместе с тем полученные результаты дают основание для того, чтобы сформулировать предварительные выводы.

Неопределенность терминов, являющихся конструктивными элементами уголовноправовых норм, устанавливающих уголовную ответственность за совершение деяний, которые могут воспрепятствовать осуществлению правосудия и производству предварительного расследования, является, на наш взгляд, основной причиной ошибок, допускаемых органами предварительного расследования при квалификации преступлений по ст. ст. 294-298.1 УК РФ. Ошибки квалификации могут быть причиной принятия процессуальных решений, которые, в свою очередь, могут иметь негативные последствия. В частности, признание на предварительном следствии прокурора «иным лицом, участвующим в отправлении правосудия» дает следователю основание квалифицировать действия лица, высказавшего в отношении прокурора угрозу убийством, причинением вреда здоровью или уничтожением имущества, а затем возбудить перед судьей ходатайство об избрании меры пресечения в виде заключения под стражу. Это обусловлено тем, что санкция ч. 1 ст. 296 УПК допускает применение наказания в виде лишения свободы на срок до трех лет, что является, согласно ч. 1 ст. 108 УПК РФ, условием для избрания данной меры пресечения. Если с такой квалификацией будет согласен судья, то вполне возможно применение меры пресечения в виде заключения под стражу без наличия к тому оснований.

Приведенные соображения дают основание поддержать высказанные в литературе предложения об исключении из текста ст. ст. 294-298.1УК РФ термина «иные лица, участвующие в отправлении правосудия» и включении в них термина «арбитражные заседатели».

Значительно сложнее представляется решение вопроса об устранении неопределенности терминов «правосудие» и «отправление правосудия». Едва ли этого можно достичь путем внесения изменения в диспозиции статей УК РФ, в которых используются данные термины. На наш взгляд, оптимальной представляется формулировка понятий правосудия и отправления правосудия в виде примечаний к ст. 294 УК РФ. Однако в качестве временной меры можно предложить Верховному Суду РФ сформулировать данные термины в постановлении Пленума, тем более необходимость принятия постановления, по нашему мнению, уже назрела в связи с тем, что в следственной и судебной практике возникают и другие вопросы, связанные с применением норм главы 31 Уголовного кодекса Российской Федерации.

\section{Список источников}

1. Анишина В.И. и др. 2011. Судебная власть и правосудие в Российской Федерации: курс лекций. Под ред. профессора В.В. Ершова. Москва, Российская Академия Правосудия, 904 с.

2. Таганцев Н.С. 1904. ...Уголовное уложение 22 марта 1903 г.: С мотивами, извлеч. из объясн. записки Ред. комис., представления Мин. юст. в Гос. сов. и журн. - особого совещ., особого присутствия деп. и общ. собр. Гос. сов. Санкт-Петербург: Гос. Тип. 1125 с.

\section{Список литературы}

1. Банников И.А. 2017. Понятие правосудия. Вестник Московского ун-та. Серия 11. Право, 1: $130-137$.

2. Бриллиантов А.В., Косевич Н.Р. 2008. Настольная книга судьи: преступления против правосудия: с учетом обобщения судебной практики, постановлений и разъяснений. Москва, ТК Велби, Издательство Проспект, 560 с.

ринского районного суда Сахалинской области № 1-29/2015 от 29 апреля 2015 г. по делу №129/2015 // https://sudact.ru/regular/doc/0FWqB0ldQnWT/ (Дата доступа: 22.10.2020). 
3. Виноградова В.А. 2015. Рассмотрение судом жалоб на действия (бездействие) и решения должностных лиц органов предварительного расследования, прокурора как новая форма осуществления правосудия. Наука и практика, 4 (65): 33-36.

4. Горелик А.С., Лобанова Л.В. 2005. Преступления против правосудия. СПб., Издательство Р. Асланова «Юридический центр Пресс», 491 с.

5. Евстигнеева О.В. 2019. Судебное заседание по рассмотрению жалоб в порядке ст. 125 УПК РФ как форма осуществления правосудия, отвечающая требованиям справедливости. Судебная власть и уголовный процесс, 1: 73-82.

6. Бимбинов А.А., Боженок С.А., Воронин В.Н., Грачева Ю.В., Жевлаков Э.Н., ИногамоваХегай Л.В., Клепицкий И.А., Корнеева А.В., Кочои С.М., Левандовская М.Г., Лошенкова Е.В., Маликов С.В., Молчанов Д.М., Орешкина Т.Ю., палий В.В., Понятовская Т.Г., Рагулина А.В., Рарог А.И., Рубцова А.С., Соктоев З.Б., Устнова Т.Д., Цепелев В.Ф., Чучаев А.И., Юрченко И.А. 2018. Комментарий к Уголовному кодексу Российской Федерации. Отв. ред. А.И. Рарог. Москва, Издательство Проспект, 912 с.

7. Прокудина Л.А. 2010. Соотношение понятий «деятельность суда» и «отправление правосудия». Право. Журнал Высшей школы экономики, 3: 43-59.

8. Рябцева Е.В. 2010. Правосудие в уголовном процессе России. Москва, Издательство Юрлитинформ, 400 с.

9. Юшина Ю.В. 2015. О целесообразности взятия под уголовно-правовую защиту деятельность лиц, содействующих суду в осуществлении функции правосудия в процессе проверки информации о совершенных или готовящихся преступлениях. В кн.: Проблемы переходного периода: адаптация нормативно-правовых актов крымского федерального округа к законодательству Российской Федерации. Материалы Всероссийской научно-практической конференции, приуроченной к годовщине вхождения Республики Крым и города федерального значения Севастополя в состав Российской Федерации. Краснодар, 13 марта 2015 г. Краснодарский университет МВД России. Крымский филиал: 405-411.

\section{References}

1. Bannikov I.A. 2017. Notion of Justice. Vestnik Moskovskogo un-ta. Ser. 11. Pravo, 1: 130137 (in Russian).

2. Brilliantov A.V., Kosevich N.R. 2008. Nastol'naya kniga sud'i: prestupleniya protiv pravosudiya : s uchetom obobshcheniya sudebnoi praktiki, postanovlenii i raz"yasnenii. [Crimes against Justice Judge's Handbook: crimes against the law-judge : with a summary of judicial practice, rulings and explanations.]. Moskva, TK Velbi, Publ. Prospekt, 560 p.

3. Vinogradova V.A. 2015. Review by the Court Complaints against Actions (Inaction) and Decision of officials of Preliminary Investigation, the public Prosecutor as a new form of realization of Justice. Nauka i praktika [Science and Practice], 4 (65): 33-36 (in Russian)

4. Gorelik A.S., Lobanova L.V. 2005. Prestupleniya protiv pravosudiya [Crimes against Justice]. $\mathrm{SPb} .$, Publ. R. Aslanova «YUridicheskij centr Press», 491 p.

5. Evstigneeva O.V. 2019. Court Session on Consideration of Complaints in Accordance with art. 125 of the code of Criminal Procedure as a form of Justice that Meets the Requirements of Justice. Sudebnaya vlast' i ugolovnyj process, 1 : 73-82 (in Russian).

6. Bimbinov A.A., Bozhenok S.A., Voronin V.N., Gracheva Yu.V., Zhevlakov E.N., Inogamova-Khegai L.V., Klepitskii I.A., Korneeva A.V., Kochoi S.M., Levandovskaya M.G., Loshenkova E.V., Malikov S.V., Molchanov D.M., Oreshkina T.Yu., Palii V.V., Ponyatovskaya T.G., Raguli-na A.V., Rarog A.I., Rubtsova A.S., Soktoev Z.B., Ustnova T.D., Tsepelev V.F., Chuchaev A.I., Yurchenko I.A. 2018. Commentary on the Criminal Code of the Russian Federation. Ed. A.I. Rarog. Moscow, Publ. Prospekt, 912 p. (in Russian)

7. Prokudina L.A. 2010. Sootnoshenie ponyatij «deyatel'nost' suda» i «otpravlenie pravosudiya» [Correlation of the Concepts of 'Court Activity' and 'Administration of Justice']. Pravo Zhurnal Vysshei shkoly ekonomiki, 3: 43-59.

8. Ryabceva E.V. 2010. Pravosudie v ugolovnom processe Rossii [Justice in the Russian Criminal Practice]. Moscow, Publ. YUrlitinform, 400 p.

9. YUshina YU.V. 2015. O celesoobraznosti vzyatiya pod ugolovno-pravovuyu zashchitu deyatel'nost' lic, sodejstvuyushchih sudu $\mathrm{v}$ osushchestvlenii funkcii pravosudiya $\mathrm{v}$ processe proverki 
informacii o sovershennyh ili gotovyashchihsya prestupleniyah [On the Expediency of Taking under Criminal Law Protection the Activities of Persons who Assist the Court in the Exercise of the Function of Justice in the Course of Verifying Information about Crimes Committed or Planned]. In: Problemy perekhodnogo perioda: adaptaciya normativno-pravovyh aktov krymskogo federal'nogo okruga $\mathrm{k}$ zakonodatel'stvu rossijskoj federacii. Materialy Vserossijskoj nauchno-prakticheskoj konferencii, priurochennoj $\mathrm{k}$ godovshchine vhozhdeniya Respubliki Krym i goroda federal'nogo znacheniya Sevastopolya v sostav Rossijskoj Federacii [Problems of the transition period: adaptation of legal acts of the Crimean Federal district to the legislation of the Russian Federation. Materials of the all-Russian scientific and practical conference dedicated to the anniversary of the entry of the Republic of Crimea and the Federal city of Sevastopol into the Russian Federation]. Krasnodar, March 13, 2015. Krasnodarskij universitet MVD Rossii. Krymskij filial: 405-411.

\section{ИНФОРМАЦИЯ ОБ АВТОРАХ}

Шумилин Сергей Федорович, доцент, доктор юридических наук, профессор кафедры уголовного процесса Белгородского юридического института МВД России имени И.Д. Путилина, г. Белгород, Россия

Новикова Екатерина Анатольевна, кандидат юридических наук, начальник кафедры уголовного процесса Белгородского юридического института МВД России имени И.Д. Путилина, г. Белгород, Россия

Шумилина Оксана Сергеевна, доцент, кандидат юридических наук, заведующая кафедрой уголовного прав и процесса юридического института Белгородского государственного национального исследовательского университета, г. Белгород, Россия.

\section{INFORMATION ABOUT THE AUTHORS}

Sergey F. Shumilin, Associate Professor, Doctor of Law, Professor of the Criminal Procedure Department of the I. D. Putilin Law Institute of Belgorod of the Ministry of Internal Affairs of Russia, Belgorod, Russia

Ekaterina A. Novikova, $\mathrm{PhD}$ in Law, Head of the Criminal Procedure Department of the I.D. Putilin Law Institute of Belgorod of the Ministry of Internal Affairs of Russia, Belgorod, Russia

Oksana S. Shumilina, Associate Professor, PhD in Law, Head of the Criminal Law and Procedure Department of the Law Institute of the Belgorod State National Research University, Belgorod, Russia. 